Review

\title{
The role of regulatory neuropeptides and neurotrophic factors in asthma pathophysiology
}

\author{
Oxana Yu. Kytikova, Tatyana P. Novgorodtseva, Marina V. Antonyuk, Tatyana A. Gvozdenko \\ Vladivostok Branch of Far Eastern Scientific Centre of Physiology and Pathology of Respiration, Scientific Research Institute of Medical \\ Climatology and Rehabilitation Treatment, Vladivostok, Russia
}

Received 15 January 2019, Revised 7 April 2019, Accepted 8 August 2019

(C) 2019, Kytikova O.Yu., Novgorodtseva T.P., Antonyuk M.V., Gvozdenko T.A.

(C) 2019, Russian Open Medical Journal

\begin{abstract}
In the last decade, the attention of scientists in the field of biomedicine is focused on studying the relationship between the immunological and neurogenic components of the inflammatory response and their contribution to the pathophysiology of allergic inflammation in asthma. The review is devoted to detailing the mechanism of neurogenic inflammation involving regulatory neuropeptides (substance $P$, vasoactive intestinal peptide, calcitonin gene-related peptide) in the pathogenesis of bronchial hyperreactivity in asthma. The role of neurotrophic growth factors (nerve growth factor, brain-derived neurotrophic factor) in the regulation of remodeling of bronchi in asthma has been analyzed. The study of neuroimmune mechanisms in the pathophysiology of asthma will it possible to find new therapeutic targets in this research area.
\end{abstract}

Keywords: asthma, neurotrophic factors, regulatory neuropeptides, chronic inflammation, neuroimmune mechanisms

Cite as Kytikova OYu, Novgorodtseva TP, Antonyuk MV, Gvozdenko TA. The role of regulatory neuropeptides and neurotrophic factors in asthma pathophysiology. Russian Open Medical Journal 2019; 8: e0402.

Correspondence to Oxana Yu. Kytikova. Address: 73g, Russkaya st., Vladivostok, Russian Federation, 690105. Phone: +7(423)2788-201. E-mail: kytikova@yandex.ru.

\section{Asthma}

Asthma is a common socially significant allergic pathology and global health problem $[1,2]$. Despite the expected increase in the number of patients, asthma is successfully controlled and treated [3]. However, about $10 \%$ of patients suffer from refractory asthma [4] that indicates a multi-factorial nature of the disease and the complexity of pathophysiological mechanisms underlying chronic inflammation [5].

Asthma is a heterogeneous disease characterized by chronic inflammation and hyperreactivity of the bronchi, which form clear clinical symptoms of the disease [6]. Hyperreactivity accompanying asthma is a direct result of persistent airway inflammation, bronchial remodeling, smooth muscle hyperplasia and impaired neuroregulation of bronchial tone. However, the factors involved in the development of bronchial hyperreactivity have not been fully disclosed, despite an impressive amount of research on this issue [7].

There are several mechanisms to maintain pulmonary homeostasis, which involve nerve and immune cells [8]. An increase in the burden of allergic diseases worldwide has enhanced researcher's interest in studying the role of immune and neurogenic mechanisms in the pathophysiology of allergic inflammation [9]. B.J. Canning et al. have emphasized the obvious but underestimated compared to the immune system role of the nervous system in asthma pathogenesis [7]. It has been established that the interaction between nerve and immune cells is disturbed in asthma, therefore this process is referred to as "neurogenic inflammation" [10]. Neurogenic inflammation is considered as an important cause of bronchial hyperresponsiveness in asthma. The immune system mediates the development of hyperresponsiveness and subsequent bronchospasm in asthma by activating sensory neurons through inflammatory mediators. Conversely, neurons modulate the development of Th2-mediated immune response, which is responsible for chronicity of inflammation, by interacting with immune cells through neurotransmitters or neuropeptides. Thus, the existence of interactions between neurons and immune cells, which play an important role in asthma pathogenesis [11], is evident. In addition, an allergic reaction is associated with local production and release of neurotransmitters, so neurogenic inflammation may accompany already existing allergic inflammation.

There are several reviews of available literature on this problem $[12,13]$. The presence of neuroimmune interrelations in asthma and their contribution to the pathogenesis of the disease have been described in the review authored by N. Kabata and D. Artis [12]. The involvement of cytokines, neuropeptides, and neurotransmitters in the cooperation of immune cells and the central, peripheral, sympathetic and parasympathetic nervous systems in asthma have been evidenced. S.L. Foster et al. has summarized the results indicating the important role of nociceptors in the regulation of immune reactions in inflammatory diseases of the bronchopulmonary system [13]. The aim of this review is to summarize the available information in order to attract the attention of researchers to a close relationship 
between the immune and nervous systems and their role in asthma pathogenesis.

The study of the role of neuroimmune mechanisms in asthma pathophysiology will allow finding new therapeutic targets in this field of research.

Adrenergic, cholinergic and non-adrenergic non-cholinergic (NANC) nerves innervate the airways [14]. Non-myelinated, nociceptive C-fibers of the lungs are involved in the sensory innervation of the mucous membrane of the airways and are responsible for the formation of the main protective reflexes [15]. Several studies suggest that sensory nerves of the respiratory tract are involved in asthma pathogenesis $[15,16]$. It has been noted that the number of nociceptors significantly increases in patients with asthma [17]. Besides that, in this pathology denser network of nociceptor fibers is localized around the small airways, the dysfunction of which is present in the majority of patients with asthma and often associated with the more severe course of the disease [18]. Nociceptors contribute to the pathogenesis of airway inflammation by initiating local neurogenic inflammation [19] and activating the bronchoconstrictor mechanism [20].

The sensitivity of nociceptors is related to the activity of transient receptor potential ion channels (TRP ion channels), in particular, TRP vanilloid receptor 1 (TRPV1) and TRP ankyrin receptor 1 (TRPA1) [21]. It is considered that chronic respiratory tract inflammation and mucus hypersecretion are associated with TRPV1 sensitization [22]. The enhanced expression of TRPV1 has been observed in asthma and is more significant in severe uncontrolled course of the disease [23]. Recent studies have shown that TRPA1 is the main trigger for the release of neuropeptides during stimulation of peripheral parts of a nociceptor and one for the development of neurogenic inflammation of the bronchial tree [24].

Neuropeptides are the largest and the most diverse class of intercellular signaling molecules secreted by neurons [25]. Neuropeptides do not belong to the parasympathetic or sympathetic nervous system and are referred to as non-adrenergic non-cholinergic peptides [26]. These signaling molecules have a wide range of regulatory functions: from neurohormones and neurotransmitters to neuromodulators that makes the study of them relevant for modern pulmonology.

There are a small number of review articles devoted to the role of regulatory neuropeptides in asthma pathogenesis $[27,28$, 29]. The information on the expression of certain neuropeptides (substance $P$, vasoactive intestinal peptide, calcitonin generegulated peptide, tachykinins, neuropeptide $Y$ (NPY), bombesins, granins), which can influence on the pathogenesis of a number of bronchopulmonary diseases, in particular asthma, is provided in the review authored by K.R. Atanasova and L.R. Reznikov [27]. The data on known and proposed receptors mediating their actions have been summarized. The effect of neuropeptides on mucus secretion in this pathology has been also described. K. Kaczyńska et al. provides a brief overview of the functions of a number of neuropeptides (leptin, substance $P$, neurotensin) in normal respiration and in chronic pulmonary pathology [28]. A.K. Verma et al. have structured and detailed the available information on the vasoactive intestinal peptide and its role in the recruitment of inflammatory cells in asthma [29]. This review summarizes the literature data on the contribution of the most studied neuropeptides (substance $P$, vasoactive intestinal peptide, calcitonin gene-regulated peptide) to the pathogenesis of bronchial hyperreactivity in asthma. Special attention was paid to the study of the effect of neuropeptides on the regulation of immune mechanisms in this pathology.

\section{Regulatory neuropeptides}

Currently, it is known that the multifaceted pathogenesis of asthma is characterized by not only inflammatory mechanisms initiated by allergic reactions but also neurogenic inflammatory mechanisms involving neuropeptides that play an important role in the nervous system control of the bronchial tree tone. There is limited evidence of the role of neuropeptides in the regulation of mucus secretion in asthma [27].

More than 10 regulatory neuropeptides have been found in the human lung, among which substance $P(S P)$, vasoactive intestinal peptide (VIP) and calcitonin gene-related peptide (CGRP) are the most studied. Neuropeptides can also be released from peripheral neurosecretory cells located in the distal parts of the respiratory tract in close proximity to the microcirculatory bloodstream and smooth muscle of the bronchi. The activation of sensory neurons leads to the release of SP and CGRP in the airways through the axon reflex mechanisms [4]. Altered CGRP, VIP and SP levels in allergic inflammation affect the regulation of immune mechanisms and, therefore, are involved in asthma pathogenesis [30]. In addition, the imbalance between stimulating (SP) and inhibiting (CGRP) neuropeptides in prolonged inflammation of the respiratory tract leads to the predominance of the stimulating environment in airway mucosa.

$\mathrm{SP}$ is a neurotransmitter of non-cholinergic excitatory nerves and is currently considered as a mediator of neurogenic inflammation, which can initiate swelling, mucus hypersecretion and bronchospasm. This pleiotropic peptide that has specific neural activity is also an immunomodulator [31]. Mast cell proteases can enhance neurogenic inflammatory reactions by releasing of SP [32]. It has been established that SP can stimulate the production of granulocyte-macrophage colony-stimulating factor (GM-CSF), which regulates the proliferation and the differentiation of progenitors of monocytes, neutrophils, macrophages and dendritic cells. SP has the ability to activate the release of pro-inflammatory cytokines (interleukin 1 (IL-1), interleukin 6 (IL-6), interleukin 8 (IL-8), tumor necrosis factor $\alpha$ (TNF $\alpha)$ ) from human bronchial epithelial cells. The data of $J$. Zhuang et al. indicate that IL-1 $\beta$ significantly intensifies SP expression and vascular permeability by the effect on C-fibers of the bronchi (PCF) that after the activation promotes the release of SP and cause bronchospasm. IL-1 $\beta$ administered systemically or locally into the lung parenchyma stimulates PCFs [33]. SP also induces the expression of intercellular adhesion molecule 1 (ICAM$1)$, which contributes to the survival of dendritic cells. According to R. Ramalho et al., SP acting via its receptor neurokinin-1 (NK1-R) plays an important role in asthma associated with obesity [34]. NK1-R blockade in mice with asthma and obesity resulting in the normalization of metabolic and systemic levels of biomarkers, as well as positive effect on allergic sensitization and inflammation in the bronchi. Presented facts allow considering this neurotransmitter as a potential therapeutic target for the treatment of this asthma phenotype.

Asthma is a chronic inflammatory disease; Th2 cells, regulatory T cells (Tregs), mast cells, eosinophils, neutrophils, epithelial and endothelial cells, fibroblasts and smooth muscle cells are involved in its pathogenesis. VIP affects all these cells and is the main 
neurotransmitter of the non-adrenergic-non-cholinergic system [35]. VIP, as one of the most common neuropeptides of the human body, is expressed in the lungs and the nasal mucosa. The action of VIP depending on the target organ and the presence of VIPassociated receptor [36]. This peptide exhibits a wide range of reactions by interacting with following receptors: VIP receptor type-1 (VPAC-1), VIP receptor type-2 (VPAC-2), chemoattractant Receptor-Homologous Molecule Expressed on Th2 cells (CRTH2) and pituitary adenylate cyclase-activating polypeptide (PACAP) receptor (PAC1), which are expressed on eosinophils, mast cells, neutrophils and lymphocytes [37]. VPAC1 is more common in lung tissue, whereas VPAC2 is presented in smooth muscles and bronchial mucosa [38]. The activity of neutral endopeptidase (NEP) is essential for the realization of properties of neuropeptides. NEP proteolyzes and inactivates neuropeptides. It is possible that the change in NEP activity also plays important role in asthma exacerbation. VIP is an endogenous vaso- and bronchodilator [29]. Besides that, it has immunomodulatory functions, including the suppression of humoral immune response, inflammatory process and remodeling of the bronchi. VIP inhibits T-lymphocyte proliferation, affects T-helper differentiation (Th2/Th1) and contributes to the induction of Tregs. In addition, there is evidence that VIP suppresses Toll-like receptor-4 (TLR-4), which plays an important role in the innate immune system [39]. There are conflicting data on its effect on mast cell degranulation and chemokine production [40]. The formation of airway hypersensitivity and reflex bronchospasm may be associated with the increased degradation of this neuropeptide. J. Wang et al. has been found that VIP inhibits airway remodeling under in vivo conditions [41]. Using mouse asthma models, it has been shown that Th17/Treg imbalance is closely associated with airway inflammation and VIP reduces this inflammation by regulating the balance of these cells [42]. S. Talbot et al. has been revealed that IL-5 acts directly on nociceptors, resulting in the release of VIP, which stimulates $\mathrm{CD}^{+}$lymphocytes and resident innate lymphoid cells of type 2, thereby creating a signal loop that contributes to allergic inflammation [15].

Thus, VIP as an important signaling molecule of the neuroendocrine-immune network is a new therapeutic target for asthma.

CGRP is involved in asthma pathophysiology [8]. CGRP is a 37 amino acid neuropeptide that was discovered in the result of alternative preparing of ribonucleic acid (RNA) copies obtained from the calcitonin gene. CGRP messenger RNA (mRNA) is detected in nerve cells that closely contact with the blood vessels. CGRP is expressed by cells of the central and peripheral nervous systems [43]. CGRP released from the nerve fibers of airways acts as a chemoattractant for $\mathrm{CD}^{+} \mathrm{T}$ lymphocytes, $\mathrm{CD} 8^{+} \mathrm{T}$ lymphocytes, eosinophils and dendritic cells [44]. In addition, CGRP is the powerful arterial and venous vasodilator.

An increase in CGRP expression in airways epithelial cells has been observed in asthma patients [45]. In addition, asthma patients have elevated levels of pulmonary neuroendocrine cells (PNEC), which are located between the epithelial cells of the respiratory tract in close proximity to group 2 innate lymphoid cells (ILC2) that affect cytokine production. PNECs stimulate ILC2s and intensify allergic reactions in asthma via CGRP [46]. It was recently described that the maturation and differentiation of dendritic cells, which play a key role in allergic sensitization in asthma patients, is modulated by CGRP [8]. CGRP inhibits dendritic cell maturation and allergen-specific $\mathrm{T}$-cell responses that influence the outcome of allergic airway inflammation in vivo [47]. These facts indicate an additional mechanism of the impact of neurotransmitters on the local immune response. Besides that, the physiological significance of CGRP in the production of interleukin9 (IL-9), which is a Th2 cytokine and involved in allergic inflammation, has been demonstrated.

Thus, CGRP as an anti-inflammatory mediator is a new and effective therapeutic target for asthma.

\section{Neurotrophic growth factors}

It is known that persistent inflammation in the bronchi leads to structural changes in the respiratory tract that probably play a certain role in the formation of bronchial hyperreactivity. Along with passive response to bronchoconstrictor stimuli (bronchial hyperreactivity), the airways are remodeled by increasing airway smooth muscles (hypertrophy and hyperplasia). Airway smooth muscle remodeling is regulated through a number of mechanisms, including the production of cytokines and neurotrophic growth factors (neurotrophins), which may have both negative and positive effects. Neurotrophins and their receptors have been recently found in the lungs (bronchial and alveolar epithelium, smooth muscles, fibroblasts and vascular endothelium). The discovery has attracted researchers' interest in the role of these molecules in the regulation of pulmonary structure and function, as well as in the pathophysiological mechanisms of bronchopulmonary diseases [48]

A number of reviews were focused on the role of neurotrophins in the pathophysiology of chronic inflammation in asthma $[48,49,50]$. The article by Y.S. Prakash et al. is of interest [48]. It considers the potential role and functions of neurotrophins in normal lung functioning and in their pathology. The characteristic of neurotrophic factors and their receptors has been given; their signaling function in the innervation of the respiratory tract and in immune cells has been analyzed. J. Barrios and Ai X. have also compiled recent literature data on neurotrophins and their receptors [49]. Special attention is given to the study of their role in the pathophysiology of early stages of asthma in children. S. Manti et al. have provided a comprehensive description of the neuroimmune interactions underlying the pathophysiology of asthma [50]. Neurotrophins have been shown to play an important role in the implementation of signaling interrelations between immune cells and the structures of the neurosensory network of the respiratory tract.

Due to the fact that this issue is not fully studied and relevant for further research, this review summarizes the available information. Particular attention is focused on the members of the neurotrophin subfamily, which can play a key role in asthma pathophysiology. The function of neurotrophic factors (nerve growth factor, brain-derived neurotrophic factor) in the regulation of bronchial remodeling in asthma has been analyzed. Based on the analysis of various literature data, the essential role of neurotrophins in the pathogenesis of this disease and the need for further research in this field are assumed.

The family of neurotrophic growth factors consist of neurotrophin 3 (NT3), neurotrophin 4 (NT4), nerve growth factor (NGF), brain-derived neurotrophic factor (BDNF), ciliary neurotrophic factor (CNTF), glial cell line-derived neurotrophic factor (GDNF), insulin-like growth factor $1 / 2$ receptor (IGF1/2) and etc. 
Neurotrophins are divided into three subfamilies: the neurotrophin subfamily (NGF, BDNF, NT3 and NT4), the glial factor subfamily (GDNF, neurturin (NTR), artemin (ART) and persephin (PSP)) and the ciliary factor subfamily (CNTF, oncostatin M (OSM), leukemia inhibitory factor (LIF) and interleukin-6 (IL6).

The members of the neurotrophin subfamily make a special contribution in airway inflammation. It is important to notice that NTs, which control the functioning of all parts of the nervous system, can regulate most pathophysiological processes by initiating a strictly specific signaling cascade of reactions. Neurotrophins mediate their effects via the high-affinity tyrosine kinase receptors (TrkA, TrkB, TrkC) and p75 Neurotrophin Receptor (p75(NTR)). At the same time, NGF predominantly interacts with TrkA, BDNF does with TrkB and p75(NTR), NT3 does with TrkC and TrkA [51].

BDNF is produced by epithelial and smooth muscle cells, sensory neurons and a number of immune cells that are involved in the pathogenesis of bronchopulmonary diseases [48]. Some research suggests that environmental trigger factors for respiratory diseases (changes in temperature and humidity, airborne pathogens, pollen, smoke particles and ozone) [51] enhance the expression of BDNF and its receptors in smooth muscle cells. It has been shown that oxidative stress induced by cigarette smoke increases the expression of BDNF and its receptors by smooth muscle cells [52]. Interestingly, neurokinins, such as substance $P$, also enhance the expression of BDNF and its receptor. The relevance of the study of BDNF action on the respiratory tract is caused by recent data indicating an increase in BDNF level in asthma. However, the question of the functional significance of BDNF in this pathology remains unresolved. Taking into account the intensification of BDNF expression in asthma, researchers assume the role of BDNF in airway inflammation, the initiation of remodeling and bronchial hyperreactivity. However, the mechanisms of BDNF action on smooth muscle cells are not fully understood. It is known that BDNF-associated receptors (TrkB, p75(NTR)) activate multiple signaling pathways, including ERK (mitogen-activated protein kinase (MAPK) signaling pathway named after the key MAP-kinase - extracellular signal-regulated kinase (ERK)) and PI3K/AKT/mTOR (intracellular signaling pathway, the components of which are following enzymes: phosphoinositide-3-kinase (PI3K), AKT and rapamycin-sensitive mTOR-complex (mTOR) kinases, phospholipase $C$ and in the case of $p 75(N T R)$ - nuclear factor KB (NF-KB)). The involvement of ERK and $\mathrm{PI3K} / \mathrm{AKT} / \mathrm{mTOR}$ pathways, which are responsible for cell proliferation, in BDNF signaling, as well as the expression of TrkB and $\mathrm{p75}$ (NTR) in human smooth muscle cells suggest the influence of BDNF on the proliferation of smooth muscle cells. B. Aravamudan et al. have demonstrated that BDNF enhances the proliferation of smooth muscle cells along with pro-inflammatory cytokines (TNF- $\alpha$ and IL-13) [53]. This scientific group has also shown that BDNF impact on $\mathrm{Ca}^{2+}$ regulation in smooth muscle cells and potentiates the effect of the pro-inflammatory cytokine TNF- $\alpha$ on $\mathrm{Ca}^{2+}$ level. The established BDNF effects on smooth muscle cell proliferation appear to be related to TrkB. However, despite the fact that p75(NTR) didn't influence on the proliferation induced by BDNF, both TrkB and p75(NTR) reduced the proliferative activity of cells in the control group. The activation of ERK1/2 signaling pathway is an important aspect of smooth muscle cell proliferation. NF-KB signaling pathway plays an important role in the mechanism of impact of BDNF on cell proliferation. Involving the PI3K/AKT/mTOR signaling pathway, which is responsible for cell proliferation, in mediating the effects of BDNF on cell proliferation suggests an alternative way to activate NF-KB.

The described literature data indicate the urgency of further research on BDNF effects on the airways.

NGF, which is known for its role in the physiology and the pathology of the nervous system [48], is recently considered as an important factor associated with the pathogenesis of allergic diseases, in particular asthma. The elevated NGF level is a stimulus for the development of pain syndrome, but the mechanisms underlying this process remain unknown. The role of NGF in the Th2-mediated immune response in asthma has been shown under experimental conditions. A number of studies have confirmed that NGF blocking inhibits allergic airway inflammation in a mouse model of asthma by modulating the balance of Th1 and Th2 cells. The increased NGF expression has been observed in asthma patients in response to bronchial provocation with an allergen and is closely related to the disease severity [54]. The results obtained by J.S. Kim et al. have shown that NGF level correlates with the number of eosinophils, which are the main effector cells in asthma [55]. High expression of NGF and tissue inhibitor of metalloproteinase-1 (TIMP-1) and the correlation between their levels in asthma patients indicate a relationship between NGF and TIMP-1, which may play an important role in asthma pathogenesis. $\mathrm{N}$. Renz et al. have revealed that NGF contributes to airway remodeling in asthma [54]. However, it is necessary to stress that the role of NGF in the pathophysiology of chronic inflammation in asthma remains not fully understood and requires further research.

\section{Conclusion}

Asthma is a heterogeneous disease characterized by chronic inflammation and bronchial hyperreactivity. Hyperreactivity is a direct consequence of persistent airway inflammation, bronchial remodeling, smooth muscle hyperplasia and impaired neuroregulation of bronchial tone. There are several mechanisms involving nerve and immune cells to maintain pulmonary homeostasis. In the past decade, the attention of researchers has been focused on studying the contribution of the relationship between immune and nervous systems in allergic inflammation in asthma. The immune system mediates bronchospasm in asthma by activating sensory neurons through inflammatory mediators. Conversely, neurons modulate the development of Th2 immune response, which is responsible for chronic inflammation, by interacting with immune cells via neurotransmitters or neuropeptides. In addition, an allergic reaction is associated with the production and release of neurotransmitters, so neurogenic inflammation can accompany and aggravate the existing allergic inflammation in asthma.

Nowadays it is obvious that asthma pathogenesis involves not only inflammatory mechanisms triggered by allergic reactions but also neurogenic inflammatory mechanisms including neuropeptides, which play an important role in bronchial hyperreactivity in asthma. Asthma is characterized by bronchial hyperreactivity (passive response) and airway smooth muscle hypertrophy and hyperplasia. Airway smooth muscle remodeling is regulated through a number of mechanisms, including neurotrophic growth factors.

In this review, we have summarized the available data on the contribution of the most studied neuropeptides (substance $P$, vasoactive intestinal peptide, calcitonin gene-regulated peptide) to 
the pathogenesis of bronchial hyperreactivity in asthma. Particular attention was paid to the study of the effect of the levels of neuropeptides on the regulation of immune mechanisms in this pathology. We give attention to the members of the neurotrophin subfamily that can play an important role in asthma. The role of neurotrophic factors (nerve growth factor, brain-derived neurotrophic factor) in the regulation of bronchial remodeling in asthma has been analyzed. This review will increase our understanding of the interaction between the nervous, immune systems and airway cells. The provided information will allow researchers and clinicians to evaluate the role of the immune and nervous systems in asthma pathophysiology and to highlight the importance of regulatory neuropeptides and neurotrophins. In this regard, the study of neuroimmune mechanisms in asthma pathophysiology will find new therapeutic targets for the disease.

\section{Conflict of interest}

We declare that we have no conflict of interest.

\section{References}

1. Global Initiative for Asthma. Global Strategy for Asthma Management and Prevention. 2019. https://ginasthma.org/gina-reports/.

2. Kytikova O, Gvozdenko T, Antonyuk M. Modern aspects of prevalence of chronic bronchopulmonary diseases. Bull Physiol Pathol Respir 2017; (64): 94-100. Russian. https://doi.org/10.12737/article 5936346fdfc1f3.32482903.

3. Lang DM. Severe asthma: epidemiology, burden of illness, and heterogeneity. Allergy Asthma Proc 2015; 36(6): 418-424. https://doi.org/10.2500/aap.2015.36.3908.

4. Kudo M, Ishigatsubo $\mathrm{Y}$, Aoki I. Pathology of asthma. Front Microbiol 2013; 4: 263. https://doi.org/10.3389/fmicb.2013.00263.

5. Casciano J, Krishnan J, Dotiwala Z, Li C, Sun SX. Clinical and economic burden of elevated blood eosinophils in patients with and without uncontrolled asthma. J Manag Care Spec Pharm 2017; 23(1): 85-91 https://doi.org/10.18553/imcp.2017.23.1.85.

6. Prakash YS. Airway smooth muscle in airway reactivity and remodeling: what have we learned? Am J Physiol Lung Cell Mol Physiol 2013; 305: L912-L933. https://doi.org/10.1152/ajplung.00259.2013.

7. Canning BJ, Woo A, Mazzone SB. Neuronal modulation of airway and vascular tone and their influence on nonspecific airways responsiveness in asthma. J Allergy (Cairo) 2012: 108149. https://doi.org/10.1155/2012/108149.

8. Rochlitzer S, Veres TZ, Kuhne K, Prenzler F, Pilzner C, Knothe S, et al. The neuropeptide calcitonin gene-related peptide affects allergic airway inflammation by modulating dendritic cell function. Clin Exp Allergy 2011; 41(11): 1609-1621. https://doi.org/10.1111/j.13652222.2011.03822.x

9. Sacchetti M, Segatto M, Bruscolini A, Abicca I, Cavaliere C, Lambiase A. Changes of NGF pathway in allergic rhinoconjunctivitis: a conjunctival allergen challenge study. Allergy 2018; 74(3): 605-607. https://doi.org/10.1111/all.13641.

10. Barnes PJ. Neurogenic inflammation in the airways. Respir Physiol 2001; 125(1-2): 145-154. https://doi.org/10.1016/s00345687(00)00210-3.

11. Thornton MA, Akasheh N, Walsh MT, Moloney M, Sheahan PO, Smyth $\mathrm{CM}$, et al. Eosinophil recruitment to nasal nerves after allergen challenge in allergic rhinitis. Clin Immunol 2013; 147(1): 50-57. https://doi.org/10.1016/i.clim.2013.02.008.

12. Kabata $H$, Artis D. Neuro-immune crosstalk and allergic inflammation. $J$ Clin Invest 2019; 130: 1475-1482. https://doi.org/10.1172/JCl124609.
13. Foster SL, Seehus CR, Woolf CJ, Talbot S. Sense and Immunity: ContextDependent Neuro-Immune Interplay. Front Immunol 2017; 8: 1463. https://doi.org/10.3389/fimmu.2017.01463.

14. Mazzone SB, Undem BJ. Vagal afferent innervation of the Airways in Health and Disease. Physiol Rev 2016; 96(3): 975-1024. https://doi.org/10.1152/physrev.00039.2015.

15. Talbot $S$, Abdulnour RE, Burkett PR, Lee $S$, Cronin SJ, Pascal MA, et al. Silencing Nociceptor Neurons Reduces Allergic Airway Inflammation. Neuron 2015; 87(2): 341-354. https://doi.org/10.1016/i.neuron.2015.06.007.

16. McAlexander MA, Gavett SH, Kollarik M, Undem BJ. Vagotomy reverses established allergen-induced airway hyperreactivity to methacholine in the mouse. Respir Physiol Neurobiol 2015; 212-214: 20-24. https://doi.org/10.1016/j.resp.2015.03.007.

17. Myers AC, Kajekar R, Undem BJ. Allergic inflammation-induced neuropeptide production in rapidly adapting afferent nerves in guinea pig airways. Am J Physiol Lung Cell Mol Physiol 2002; 282(4): 775-781. https://doi.org/10.1152/ajplung.00353.2001.

18. Carr TF, Altisheh R, Zitt M. Small airways disease and severe asthma. World Allergy Organ J 2017; 10(1): 20 https://doi.org/10.1186/s40413-017-0153-4.

19. Hox V, Vanoirbeek JA, Alpizar YA, Voedisch S, Callebaut I, Bobic S, et al. Crucial role of transient receptor potential ankyrin 1 and mast cells in induction of nonallergic airway hyperreactivity in mice. Am J Respir Crit Care Med 2013; 187(5): 486-493. https://doi.org/10.1164/rccm.201208-13580C.

20. Tränkner D, Hahne N, Sugino K, Hoon MA, Zuker C. Population of sensory neurons essential for asthmatic hyperreactivity of inflamed airways. Proc Natl Acad Sci U S A 2014; 111(31): 11515-11520. https://doi.org/10.1073/pnas.1411032111.

21. Lee LY, Yu J. Sensory nerves in lung and airways. Compr Physiol 2014; 4(1): 287-324. https://doi.org/10.1002/cphy.c130020.

22. Yang J, Yu HM, Zhou XD, Kolosov VP, Perelman JM. Study on TRPV1mediated mechanism for the hypersecretion of mucus in respiratory inflammation. Mol Immunol 2013; 53(1-2): 161-171. https://doi.org/10.1016/j.molimm.2012.06.015

23. McGarvey LP, Butler CA, Stokesberry S, Polley L, McQuaid S, Abdullah $\mathrm{H}$, et al. Increased expression of bronchial epithelial transient receptor potential vanilloid 1 channels in patients with severe asthma. J Allergy Clin Immunol 2014; 133(3): 704-712. https://doi.org/10.1016/j.jaci.2013.09.016.

24. Chiu IM, von Hehn CA, Woolf CJ. Neurogenic inflammation and the peripheral nervous system in host defense and immunopathology. Nat Neurosci 2012; 15(8): 1063-1067. https://doi.org/10.1038/nn.3144.

25. Hoyer D, Bartfai T. Neuropeptides and neuropeptide receptors: drug targets, and peptide and non-peptide ligands: a tribute to Prof. Dieter Seebach. Chem Biodivers 2012; 9(11): 2367-2387. https://doi.org/10.1002/cbdv.201200288.

26. Semmens DC, Mirabeau O, Moghul I, Pancholi MR, Wurm Y, Elphick MR. Transcriptomic identification of starfish neuropeptide precursors yields new insights into neuropeptide evolution. Open Biol 2016; 6(2): 150224 https://doi.org/10.1098/rsob.150224.

27. Atanasova KR, Reznikov LR. Neuropeptides in asthma, chronic obstructive pulmonary disease and cystic fibrosis. Respir Res 2018; 19(1): 149. https://doi.org/10.1186/s12931-018-0846-4.

28. Kaczyńska K, Zając D, Wojciechowski P, Kogut E, SzeredaPrzestaszewska M. Neuropeptides and breathing in health and disease. Pulm Pharmacol Ther 2018; 48: 217-224. https://doi.org/10.1016/i.pupt.2017.12.001.

29. Verma AK, Manohar M, Upparahalli Venkateshaiah S, Mishra A. Neuroendocrine cells derived chemokine vasoactive intestinal polypeptide (VIP) in allergic diseases. Cytokine Growth Factor Rev 2017; 38: 37-48. https://doi.org/10.1016/j.cytogfr.2017.09.002. 
30. Voedisch S, Rochlitzer S, Veres TZ, Spies E, Braun A. Neuropeptides control the dynamic behavior of airway mucosal dendritic cells. PLoS One 2012; 7(9): e45951. https://doi.org/10.1371/journal.pone.0045951.

31. Sun J, Bhatia M. Substance $P$ at the neuro-immune crosstalk in the modulation of inflammation, asthma and antimicrobial host defense. Inflamm Allergy Drug Targets 2014; 13(2): 112-120. https://doi.org/10.2174/1871528113666140323202419.

32. Tomljenovic D, Baudoin T, Megla ZB, Geber G, Scadding G, Kalogjera L. Females have stronger neurogenic response than males after nonspecific nasal challenge in patients with seasonal allergic rhinitis. Med Hypotheses 2018; 116: 114-118. https://doi.org/10.1016/j.mehy.2018.04.021.

33. Zhuang J, Xu J, Zhang C, Xu F. IL-1beta acutely increases pulmonary SP and permeability without associated changes in airway resistance and ventilation in anesthetized rats. Respir Physiol Neurobiol 2011; 175(1): 12-19. https://doi.org/10.1016/j.resp.2010.08.002.

34. Ramalho R, Almeida J, Beltrão M, Pirraco A, Costa R, Sokhatska O, et al. Substance $P$ antagonist improves both obesity and asthma in a mouse model. Allergy 2013; 68(1): 48-54. https://doi.org/10.1111/all.12052.

35. Wu D, Lee D, Sung YK. Prospect of vasoactive intestinal peptide therapy for COPD/PAH and asthma: a review. Respir Res 2011; 12: 45. https://doi.org/10.1186/1465-9921-12-45.

36. Szema AM, Hamidi SA, Golightly MG, Rueb TP, Chen JJ. VIP regulates the development \& proliferation of Treg in vivo in spleen. Allergy Asthma Clin Immunol 2011; 7: 19. https://doi.org/10.1186/1710-14927-19.

37. Koga M, Mizuno Y, Watanabe I, Kawakami H, Goto T. Role of VPAC2 receptor in monocrotaline-induced pulmonary hypertension in rats. $J$ Appl Physiol (1985) 2014; 117(4): 383-391. https://doi.org/10.1152/japplphysiol.00861.2013.

38. Couvineau A, Laburthe M. VPAC receptors: structure, molecular pharmacology and interaction with accessory proteins. Br J Pharmacol 2012; 166(1): 42-50. doi: https://doi.org/10.1111/i.14765381.2011.01676.x

39. Jiang $W$, Tang $W$, Geng $Q, X u$ X. Inhibition of toll-like receptor 4 with vasoactive intestinal peptide attenuates liver ischemia-reperfusion injury. Transplant Proc 2011; 43(5): 1462-1467. https://doi.org/10.1016/j.transproceed.2011.01.191.

40. Kulka M, Sheen CH, Tancowny BP, Grammer LC, Schleimer RP. Neuropeptides activate human mast cell degranulation and chemokine production. Immunology 2008; 123(3): 398-410. https://doi.org/10.1111/j.1365-2567.2007.02705.x.

41. Wang J, Shang YX, Cai XX, Liu LY. Vasoactive intestinal peptide inhibits airway smooth muscle cell proliferation in a mouse model of asthma via the ERK1/2 signaling pathway. Exp Cell Res 2018; 364(2): 168-174. https://doi.org/10.1016/i.yexcr.2018.01.042.

42. Ke LQ, Wang FM, Luo YC. Effects of vasoactive intestinal peptide on airway inflammation and Th17/Treg balance in asthmatic mice. Zhongguo Dang Dai Er Ke Za Zhi 2017; 19(6): 699-704. Chinese. https://www.ncbi.nlm.nih.gov/pubmed/28606240.

43. Messlinger K. The big CGRP flood - sources, sinks and signalling sites in the trigeminovascular system. J Headache Pain 2018; 19(1): 22. https://doi.org/10.1186/s10194-018-0848-0.

44. Le DD, Rochlitzer S, Fischer A, Heck S, Tschernig T, Sester M, et al. Allergic airway inflammation induces the migration of dendritic cells into airway sensory ganglia. Respir Res 2014; 15: 73. https://doi.org/10.1186/1465-9921-15-73.

45. Lim KG, Rank MA, Kita H, Patel A, Moore E. Neuropeptide levels in nasal secretions from patients with and without chronic cough. Ann Allergy Asthma Immunol 2011; 107(4): 360-363. https://doi.org/10.1016/j.anai.2011.07.010.

46. Sui $P$, Wiesner DL, Xu J, Zhang $Y$, Lee J, Van Dyken $S$, et al. Pulmonary neuroendocrine cells amplify allergic asthma responses. Science 2018; 360(6393). pii: eaan8546. https://doi.org/10.1126/science.aan8546.
47. Heck S, Daubeuf F, Le DD, Sester M, Bonnet D, Bals R, et al. Decreased Migration of Dendritic Cells into the Jugular-Nodose Ganglia by the CXCL12 Neutraligand Chalcone 4 in Ovalbumin-Sensitized Asthmatic Mice. Neuroimmunomodulation 2017; 24(6): 331-340. https://doi.org/10.1159/000487140

48. Prakash YS, Thompson MA, Meuchel L, Pabelick CM, Mantilla CB, Zaidi $\mathrm{S}$, et al. Neurotrophins in lung health and disease. Expert Rev Respir Med 2010; 4(3): 395-411. https://doi.org/10.1586/ers.10.29.

49. Barrios J, Ai X. Neurotrophins in Asthma. Curr Allergy Asthma Rep 2018; 18(2):10. https://doi.org/10.1007/s11882-018-0765-y.

50. Manti S, Brown P, Perez MK, Piedimonte G. The Role of Neurotrophins in Inflammation and Allergy. Vitam Horm 2017; 104: 313-341. https://doi.org/10.1016/bs.vh.2016.10.010.

51. Petruska JC, Kitay B, Boyce VS, Kaspar BK, Pearse DD, Gage FH, et al. Intramuscular AAV delivery of NT-3 alters synaptic transmission to motoneurons in adult rats. Eur J Neurosci 2010; 32(6): 997-1005. https://doi.org/10.1111/j.1460-9568.2010.07392.x.

52. Sathish V, Vanoosten SK, Miller BS, Aravamudan B, Thompson MA, Pabelick CM, Vassallo R, Prakash YS. Brain-derived neurotrophic factor in cigarette smoke-induced airway hyperreactivity. Am J Respir Cell Mol Biol 2013; 48(4): 431-438. https://doi.org/10.1165/rcmb.2012 01290C.

53. Aravamudan B, Thompson M, Pabelick C, Prakash YS. Brain-derived neurotrophic factor induces proliferation of human airway smooth muscle cells. J Cell Mol Med 2012; 16(4): 812-823. https://doi.org/10.1111/i.1582-4934.2011.01356.x.

54. Renz $\mathrm{H}$, Kiliç $\mathrm{A}$. Neurotrophins in chronic allergic airway inflammation and remodeling. Chem Immunol Allergy 2012; 98: 100-117. https://doi.org/10.1159/000336504.

55. Kim JS, Kang JY, Ha JH, Lee HY, Kim SJ, Kim SC, et al. Expression of nerve growth factor and matrix metallopeptidase-9/tissue inhibitor of metalloproteinase-1 in asthmatic patients. J Asthma 2013; 50(7): 712 717. https://doi.org/10.3109/02770903.2013.808664.

\section{Authors:}

Oxana Yu. Kytikova - MD, DSc, Researcher, Laboratory of Rehabilitative Treatment, Vladivostok Branch of Far Eastern Scientific Centre of Physiology and Pathology of Respiration, Scientific Research Institute of Medical Climatology and Rehabilitation Treatment, Vladivostok, Russia. http://orcid.org/0000-0001-5018-0271.

Tatyana P. Novgorodtseva - DSc, Professor, Chief Researcher, Laboratory of Biomedical Research, Vladivostok Branch of Far Eastern Scientific Centre of Physiology and Pathology of Respiration, Scientific Research Institute of Medical Climatology and Rehabilitation Treatment, Vladivostok, Russia. http://orcid.org/0000-0002-6058-201x.

Marina V. Antonyuk - MD, DSc, Professor, Head of the Laboratory of Rehabilitation Treatment, Vladivostok Branch of Far Eastern Scientific Centre of Physiology and Pathology of Respiration, Scientific Research Institute of Medical Climatology and Rehabilitation Treatment, Vladivostok, Russia. https://orcid.org/0000-0002-2492-3198.

Tatyana A. Gvozdenko - MD, DSc, Professor of Russian Academy of Sciences, Chief Researcher, Laboratory of Rehabilitation Treatment, Vladivostok Branch of Far Eastern Scientific Centre of Physiology and Pathology of Respiration, Scientific Research Institute of Medical Climatology and Rehabilitation Treatment, Vladivostok, Russia. http://orcid.org/0000-0002-6413-9840. 